\title{
Competência informacional: educação e sociedade
}

Mônica Regina Peres ${ }^{1}$ monicaperes@unb.br

Resumo: A necessidade em manusear vários recursos informacionais e ser capaz de recuperar de forma rápida e segura as informações necessárias, são o foco deste artigo è necessário saber lidar com as influências da tecnologia na sociedade, as necessidades informacionais dos usuários e suas competências para lidar com esses novos formatos. Essas demandas por habilidades específicas criaram uma população de excluídos, indivíduos que são colocados à margem da sociedade e em relação à formação educacional. O mercado de trabalho influência as formas de a sociedade propor formas de educação ao cidadão, neste caso, o profissional da informação passa a desenvolver importante papel não só como o profissional apto a recuperar e disseminar a informação, mas aquele que colabora no desenvolvimento das competências informacionais do usuário da informação.

Palavras-chave: Competência informacional; Necessidade de informação; Information Literacy; Profissional da Informação.

Abstract: The need to handle multiple information resources, and to be able to get quickly information recover, information security, information needs based, are the paper focuses. It is necessary to deal with the technology influences in society, their informational needs and their abilities about the new formats. These demands for specific skills eventually create excluded individuals who are outside by society and education. The labor market influence the society to propose education forms to citizens, in this case, the information professional is to develop important role not only as a professional able to retrieve and disseminate information, but he is the professional who can provide to an information user to develop informational skills.

Keywords: Information needs, Information Literacy, Information Professional.

\footnotetext{
${ }^{1}$ Mônica Regina Peres: Bibliotecária; Mestre em Desenvolvimento Regional e Meio Ambiente.
} 


\section{INTRODUÇÃO}

A necessidade da sociedade contemporânea em adquirir informações atuais e precisas, aliada à explosão informacional das últimas décadas, refletida em suportes de armazenamento diferenciados, no surgimento de repositórios e bases de dados, no aumento na velocidade de conexão e na facilidade de acesso à internet entre outros fatores, faz com que o usuário precise manusear vários desses recursos e tecnologias informacionais ao mesmo tempo, para que isso ocorra de forma habitual é preciso que o usuário conheça as formas eficazes de recuperação da informação e seja capaz de uma análise crítica do que está sendo recuperado. Essa necessidade informacional, identificada pelos profissionais da informação desde a década de 70 (DUDZIAK, 2003), atualmente está sendo abordada em várias pesquisas e estudos, como podemos encontrar nas palavras-chave dos textos utilizados nesta pesquisa: Information Literacy traduzido como Letramento Informacional, Alfabetização Informacional ou pelo contexto da Ciência da Informação como sendo o Comportamento Informacional.

O comportamento humano em busca da informação com agilidade, com segurança quanto às fontes e sua forma de uso têm sido temas de várias pesquisas sob diferentes aspectos. Todas essas mudanças têm causado novas perspectivas ao campo de atuação do profissional da informação, que foi aumentado nos aspectos relativos ao acesso e tratamento da informação:

\footnotetext{
O profissional da informação é um dos principais responsáveis pela filtragem e disseminação da boa informação ao usuário que, na maioria das vezes, não sabe distinguir o que é informação e o que é lixo informacional, até mesmo pelo fato de não dispor de habilidades para isso. (ROCHA, 2008, p. 153)
}

Esse novo cenário faz com que o profissional da informação passe a refletir sobre suas responsabilidades, atribuições e habilidades, conseqüentemente a avaliar suas reais competências para desempenhar um trabalho de qualidade perante a essa nova e tecnológica sociedade. Neste sentido, esta reflexão é composta por temas que vão do uso de novas tecnologias à busca da informação pela sociedade e propõe uma reflexão sobre a atuação dos profissionais da informação. 


\section{SOCIEDADE E TECNOLOGIA}

A sociedade contemporânea tem recebido e utilizado vários tipos de informações, independente de suporte, armazenamento ou recuperação, tornando o profissional da informação essencial para habilitar outros profissionais que, apesar de lidarem com atividades e exercerem funções relativas ao uso da informação, muitas vezes o fazem de forma precária por não possuírem habilidades individuais específicas para este fim. Apesar do tema ainda ser considerado novo, despertar ou criar a competência informacional no usuário também tem sido o objetivo de pesquisadores e profissionais envolvidos nesse processo.

Embora o conhecimento e sua comunicação sejam fenômenos básicos de toda sociedade humana, é o surgimento da tecnologia da informação e seus impactos globais que caracterizam a nossa sociedade como uma sociedade da informação (CAPURRO, 2007, p. 149).

Toda a tecnologia hoje disponível, até pouco tempo era imaginável. A tão necessária informação em todos os campos: pessoal, social e organizacional, está disponível em quantidade e velocidade que traz comodidade aos seus usuários e, na mesma proporção, traz a confusão quanto as suas formas de recuperação e a possibilidade de análise crítica por seus usuários. A sociedade sofre os impactos desta rápida evolução, fazendo com que as habilidades individuais de cada profissional em lidar com estas novas atividades sejam valorizadas.

De maneira generalizada, os projetistas de ferramentas tecnológicas (FT) pré-definem os modos de acesso e consulta à informação sem considerar o ponto de vista dos usuários. Porém, os procedimentos definidos pelos projetistas exigem que os usuários desenvolvam habilidades tais como: saber digitar; definir as buscas, decifrar e usar os vários tipos de interfaces, com pouco ou nenhum mecanismo de prevenção de erros; conhecer a sintaxe dos programas e, também, o vocabulário controlado de muitos deles, além de saber utilizar os operadores lógicos (CUNHA; KAFURE, 2006, p. 273).

Estas exigências por habilidades específicas, para o uso das tecnologias em todos os ambientes de atuação do indivíduo, acabam por criar uma população de 
excluídos, uma população que não manuseia e teme as novas tecnologias da comunicação e da informação. A dimensão desta exclusão é citada por Otterloo (2010, p.18) quando comenta como está caracterizada a sociedade mundial, ou sociedade dos três terços: "um terço integrado ao trabalho e ao consumo, um terço precarizado no trabalho e no consumo e um terço excluído." A exclusão não está só nos usos desses modernos equipamentos, quando falamos de tecnologia, englobamos também o sistema de conhecimentos e a organização necessária para produzi-la, operá-la e disseminá-la.

É nesse contexto da tecnologia relativa à produção, recuperação e disseminação que são criadas as redes sociais, que via internet possibilitam que:

\begin{abstract}
Passamos a ter formas multidirecionais de interação nesses espaços inovadores de conexão. É no fluxo das trocas, idéias, conversas e debates que surgem as construções coletivas de conhecimento e esse é um dos papéis mais importantes em uma rede: promover a interação, compartilhar conhecimentos, (re)criar conhecimentos e construir novas formas de cooperação a partir dessa dinâmica. (BARROS, MIRANDA, 2010, p.60)
\end{abstract}

Entre as muitas possibilidades, temos as redes de comunicação que atualmente nos permite o compartilhamento cultural, a preservação da memória individual ou coletiva e até o fortalecimento da identidade de uma comunidade, como afirma Francine (2010, p. 91).

O uso das tecnologias pela sociedade, seja em forma de artefato, de possibilidades de trabalho ou em forma de conhecimento, é uma realidade que ainda é desconhecida por parte de nossa população. Esse manuseio constante e a sua rapidez em inovações fazem com que todos os indivíduos, independente da área de atuação ou da área de interesse, necessitem de atualizações em suas formas de lidar com as tecnologias.

\title{
2.1 EDUCAÇÃO E TECNOLOGIA
}

A informação sempre esteve presente na história da sociedade, mesmo quando seus usuários não percebiam que faziam uso dela, como o pequeno agricultor ao 
realizar determinado plantio e garantir sua subsistência, ou o artesão quando produz suas peças únicas, enfim qualquer profissional que necessite de informação específica e atualizada. Brunner (2004, p.24) relata o difícil acesso a informação e que apenas uma minoria tinha acesso aos textos até o começo do século XIX, devido aos altos índices de analfabetismos no mundo. Hoje nas organizações a informação assume o papel da competitividade, na educação proporciona apoio as novas técnicas e a disseminação do conhecimento, faz parte de nosso cotidiano.

\begin{abstract}
A informação está presente nos mais diversos campos da atividade humana, tais como o científico, o técnico, o comercial, o organizacional e esse é um dos motivos para o seu crescente papel na vida social, cultural, política e econômica da sociedade contemporânea que a utiliza mais intensamente. Esses fatos têm despertado o interesse de pesquisadores para estudos sobre a produção, organização, acesso e uso da informação (CALAZANS, 2008, p. 30).
\end{abstract}

O atual profissional, independente da sua área de atuação, sofre grandes influências dos avanços tecnológicos, da avalanche informacional e das possibilidades de interagir globalmente.

Um estudo sobre o volume do conhecimento publicado e registrado, divulgado por Brunner (2004, p. 26), diz que a informação para ter seu volume duplicado pela primeira vez levou 1.750 anos, dobrou novamente em 150 anos, novamente duplicou seu volume com outros 50 anos e atualmente o conhecimento nestes moldes tem seu volume duplicado a cada 05 anos e estima-se que em 2020 duplicará a cada 73 dias.

Desta forma torna-se impossível tentar acompanhar toda a produção. 0 profissional que saiba recuperar e disponibilizar a informação para a sociedade será mais requerido do que os menos preparados. Essas tendências fazem com que ele procure formas de sanar suas necessidades de atualização profissional, não basta mais ter apenas boa formação acadêmica, as habilidades individuais em lidar com todas essas novidades tecnológicas são avaliadas na hora de garantir uma colocação no mercado.

Historicamente, a finalidade da formação educacional foi a de formar profissionais para um trabalho estável, por toda a vida, aptos a 
exercer uma função especializada. Atualmente, cresce cada vez mais a demanda por profissionais flexíveis, multicapacitados, capazes de aprender ao longo da vida. Informação, conhecimento e habilidade de lidar com grandes massas de informações, assim como demandas pessoais e profissionais, transformaram-se nos maiores determinantes dos avanços sociais e econômicos (DUZIAK, 2003, p. 31).

As tecnologias de informação e comunicação prestam grande contribuição ao desenvolvimento da sociedade que requer do cidadão uma educação continuada, talvez a única responsável por transformas a informação em conhecimento, garantindo a superação de deficiências e criando as competências exigidas pela nova sociedade global. É evidente que a tecnologia esteja ligada à educação, transformando suas metodologias, acrescentando conteúdos, oportunizando o aparecimento de novas habilidades.

É por isso que a incorporação de novas tecnologias na sala de aula deverá implicar um redirecionamento das competências e dos conteúdos ensinados pela escola. Além de integrar tecnologias, será preciso promover um modelo didático que tenda à construção de competências cognitivas gerais. (IAIES, 2004, p.238)

Essa incorporação de novas tecnologias e a busca por novas competências, além das exigidas pelo mercado de trabalho, mas em consonância as suas exigências, fez com que o setor educacional se modernizasse ao mesmo tempo em que colocou em dúvida a capacidade deste setor em usar adequadamente essas novas tecnologias.

De forma estranha, os discursos sobre a educação, com raras exceções, foram formulados prescindindo das bases tecnológicas da comunicação que estão na sua base. $\mathrm{Na}$ pior das hipóteses, o tecnológico aparece como um elemento alheio à educação; na melhor, como um fator externo que deve ser "trazido" para a escola e que, nessas circunstâncias, é pensado de modo puramente instrumental, como uma caixa de ferramenta que se toma emprestada para pô-la a serviço de uma missão humana transcendental (BRUNNER, 2004, p. 19). 
A atualidade nos diz que a educação está mudando do formato analógico para o digital, o fato é que não basta adquirir as Novas Tecnologias da Informação e Comunicação (NTIC) e montar os "laboratórios de informática" nas instituições de ensino, há necessidade de preparar seus docentes para o melhor uso desses elementos. As NTIC concorrem com todas as novidades de comunicação no mercado, com tecnologias já assimiladas pela sociedade como a TV, Rádio, etc. e com as novas como internet e as redes sociais. Como ensinar a recuperar e usar a informação se os docentes usam as tecnologias apenas como ferramenta didática?

\subsection{INFORMAÇÃO E COMPETÊNCIA INFORMACIONAL}

A informação sempre teve seu papel de destaque na sociedade, mas somente com suas inúmeras possibilidades de uso e de tecnologias crescentes é que podemos perceber maior valorização do profissional da informação, reconhecido como aquele capaz de ir além da busca da informação, mas também capaz de preparar o usuário para essa caminhada.

O letramento informacional também cria uma demanda de serviços de informação cada vez mais sofisticada e de alta qualidade, exigindo do profissional, além dos conhecimentos básicos, trabalho interdisciplinar, o uso do senso crítico para resolução de problemas informacionais, o saber avaliar e filtrar as informações necessárias, tornar as pessoas autônomas e independentes quanto à busca da informação (ROCHA, 2008, p. 154).

A busca da informação envolve vários aspectos do ser humano, o que comprova a necessidade de integração de todas as suas competências desenvolvidas em sua formação e as suas habilidades pessoais: 
ProcessodeBuscadaInformação

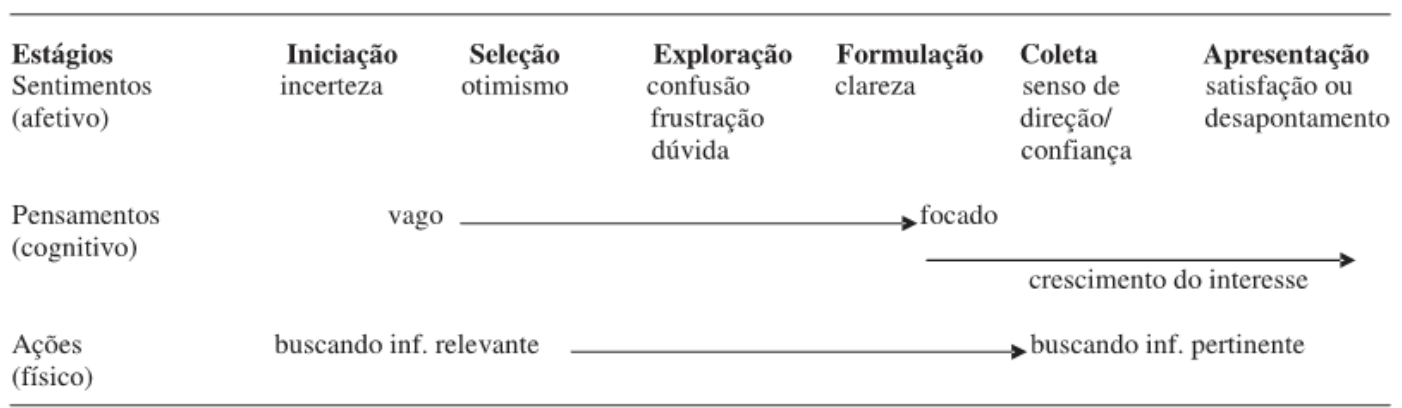

Fonte: Kuhlthau (2004, p. 82).

O profissional da informação inserido nas organizações educacionais, mais especificadamente o bibliotecário, passa a assumir também um papel de educador participativo.

Uma das funções do bibliotecário seria a de professor, encarregado de ensinar não apenas as habilidades que vinha tradicionalmente ensinando (localizar e recuperar informação), mas também envolvido no desenvolvimento de habilidades de pensar criticamente, ler, ouvir e ver, enfim ensinando a aprender a aprender (CAMPELLO, 2003, p. 30).

A autora ainda descreve o conjunto de recomendações da Information Power para desenvolvimento das competências informacionais no âmbito da educação e para isso as habilidades foram definidas em termos teóricos e na perspectiva de aplicação. "Foram incluídas nove habilidades informacionais, divididas em três grupos que abrangem: 1) competência para lidar com informação; 2) informação para aprendizagem independente; 3) informação para responsabilidade social." (CAMPELLO, 2003, p. 31). Ainda completa que:

Considerando que a competência em leitura seja fator básico para o letramento informacional, pode-se dizer que a prática do bibliotecário brasileiro encontra-se em patamar que antecede ao letramento informacional. Alguns bibliotecários estão engajados em atividades que mostram seu entendimento da necessidade de formar pessoas com capacidade de aprender com a informação, de pesquisar corretamente, de serem aprendizes autônomos, mas ainda precisam percorrer etapas para fazê-lo de forma completa (CAMPELLO, 2003, p. 203). 
É na educação que muitos indivíduos iniciam o contato com a informação de forma planejada, com objetivos específicos e com profissionais habilitados. Quando isso não ocorre, "Há dificuldade de adaptação de alguns setores (e indivíduos) ao aparato tecnológico e suas práticas com formatos e conteúdos diferenciados (multimídia)" (SIMEÃO, 2006, p. 40).

As atividades educacionais e projetos para a formação de usuários independentes para a busca e o uso da informação, estão vinculados às várias etapas do processo de formação e do envolvimento de profissionais que estejam comprometidos em colaborar para o surgimento de uma sociedade mais consciente de suas possibilidades e de suas responsabilidades quanto ao uso crítico e ético da informação.

Baseada em vários autores, Miranda (2006, p. 108) escreveu sobre o desenvolvimento de competências específicas "com base nos conceitos expostos, define-se competência como o conjunto de recursos e capacidades colocado em ação nas situações práticas do trabalho: saber (conhecimentos), saber-fazer (habilidades) e saber-ser/agir (atitudes)."

Quanto à competência informacional (MIRANDA, 2004, p. 107), essa se faz necessária a qualquer atividade profissional e identificar dentro das organizações as atividades efetivamente ligadas ao trabalho com informação, mas executadas por profissionais não preparados para tal fim, permitirá melhorias nas condições de trabalho baseadas nas próprias competências desses profissionais, tornando as atividades mais efetivas. A forma como o ser humano lida com a informação dependerão de seus próprios conceitos e suas necessidades em qualquer contexto que esteja inserido.

O campo da conduta informacional humana remete a conceitos como contextos informacionais das pessoas, necessidades de informação, comportamentos de busca da informação, modelos de acesso à informação, recuperação e disseminação, processamento humano e uso da informação. Seu desenvolvimento está baseado na crença de que a informação é essencial ao funcionamento e interação dos indivíduos, grupos sociais, organizações e sociedades e para melhorar a qualidade de vida (FIALHO, 2005, p. 21). 
O trabalho de Campello (2003) cita o uso e a tradução do termo information literacy por diversos autores e o "potencial desse conceito como catalisador das mudanças do papel da biblioteca em face das exigências da educação no século XXI".

Para chegar à expressão Competência Informacional, faz-se necessário o uso do termo information literacy segundo Duziak (2003, p. 24), que "é uma expressão que ainda não possui tradução para a língua portuguesa. Porém, algumas expressões possíveis seriam alfabetização informacional, letramento, literacia, fluência informacional, competência em informação."

A utilização da expressão competência em informação parece ser a mais adequada em função de sua definição voltar-se a um saber agir responsável e reconhecido, que implica mobilizar, integrar, transferir conhecimentos, recursos, habilidades, que agreguem valor direcionados à informação o e seu vasto universo. (DUZIAK, 2003, p. 24).

As colocações dos autores citados levam a pensar que o futuro do profissional da informação está em proporcionar o desenvolvimento de competências informacionais por parte dos usuários, independente onde esteja esse usuário, se já no mercado de trabalho em plena formação educacional.

\section{REFLEXÕES FINAIS}

No Dicionário de Biblioteconomia e Arquivologia (CUNHA, 2008, p. 10) temos a definição para competência informacional a partir do sinônimo de alfabetização informacional, "conjunto de competências que uma pessoa possui para identificar a informação, manipular fontes de informação, elaborar estratégias de busca e localizar a informação (...)", o que nos levar a perceber que as competências informacionais são de caráter individual e único. A rápida expansão das tecnologias de comunicação e informação proporcionou maior visibilidade ao profissional da informação ao mesmo tempo valorizando a informação no contexto que ela for utilizada.

O aperfeiçoamento da infra-estrutura informacional ampliou as capacidades de armazenagem, recuperação, classificação, filtragem e 
distribuição, aumentando o valor agregado à própria informação, como também a habilidade dos profissionais especializados em tratála e gerenciá-la (SIMEÃO, 2006, p. 36-38).

O profissional da informação passou a atuar como um facilitador da informação, em um processo dinâmico e consciente de seu papel na sociedade, “(...) o sujeito assume identidades diferentes em diferentes momentos, afetadas tanto pelos processos de socialização quanto de globalização dos meios de comunicação e informação" (MIRANDA, 2003, p. 69).

No decorrer do texto, percebe-se que a competência informacional está ligada as habilidades do indivíduo, ao ambiente social e organizacional que ele atua e as necessidades informacionais dos usuários que ele atende. Os processos de aquisição a estas competências pelos usuários de informação dependem dos avanços tecnológicos disponíveis e não é realizado de forma autônoma, necessita de um facilitador da área.

Conforme diz Miranda (2006, p. 102) "o comportamento informacional pode ser definido como a totalidade do comportamento em relação a fontes e canais de informação, incluindo a busca passiva e ativa e o uso de informação."

No âmbito da produção, as relações entre modernidade, novas tecnologias, educação e trabalho traz várias implicações na formação profissional. Essas novas relações ainda parecem excludentes, pois permanecem restritas aos indivíduos que preenchem os novos requisitos informacionais a partir de padrões determinados pelo setor produtivo. Corremos o risco, enquanto profissionais da informação, de perpetuar as diferenças sociais identificadas na sociedade, visto que o acesso apesar de irrestrito culmina no uso de tecnologias nem sempre acessíveis.

\section{Referências}

BARROS, L., MIRANDA, I. O papel das redes sociais para a construção e o compartilhamento do conhecimento em Tecnologias Sociais. In: REDE DE TECNOLOGIA SOCIAL. (Brasil) (Org.). Tecnologia Social e Desenvolvimento Sustentável. Brasília: Secretaria Executiva da Rede de Tecnologia Social, 2010. p. 59-63. 
BRUNNER, J. J. Educação no encontro com as novas tecnologias. In: TEDESCO, J. C. (org.). Educação e Novas Tecnologias: esperança ou incerteza? São Paulo: Cortez. 2004. p.17-75.

CALAZANS, A. T. S. Qualidade da informação conceitos e aplicações. Transinformação, Campinas, v. 20, p. 10-20, 2008.

CAMPELLO, Bernadete. O movimento da competência informacional: uma perspectiva para o letramento informacional. Ciência da Informação, Brasília, v.2, n.3, p.28-37, set./dez. 2003. Disponível em: <http://www.scielo.br/pdf/ci/v32n3/1902 1.pdf>. Acesso em: 26 de dez. 2010.

Perspectivas de Letramento Informacional no Brasil: práticas educativas de bibliotecários em escolas de ensino básico. Enc. Bibli: R. Eletr. Bibliotecon. Ci. Inf., Florianópolis, v. 15, n. 29, p.184-208, 2010. Disponível em: <http://www.periodicos.ufsc.br/index.php/eb/article/view/10470/12426> Acesso em: 26 de dez. 2010.

CAPURRO, R.; HjØrland, B. O conceito de informação. Perspectivas em Ciência da Informação, Belo Horizonte, v.12, n.1, p. 148-207, abr. 2007. Disponível em: <http://www.eci.ufmg.br/pcionline/> Acesso em: 05 de maio 2009.

DUZIAK, Elisabeth Adriana. Information literacy: princípios, filosofia e prática. Ciência da Informação, Brasília, v.32, n.1, p.23-35, abr. 2003. Disponível em: <http://www.scielo.br/pdf/ci/v32n1/15970.pdf>. Acesso em: 26 de dez. 2010.

FIALHO, Janaina Ferreira; MOURA, Maria Aparecida. A Formação do pesquisador juvenil. Perspectivas em Ciência da Informação, Belo Horizonte, v.10, n2, p.194-207, jul./dez., 2005.

Disponível

em:

<http://www.cci.ufsfmg.br/pcionline/vicwanticte.oho?id=413\&iahout=abstract>

Acesso em: 26 de dez. 2010.

FRANCINE, S. O papel da Tecnologia Social para a promoção de cidades sustentáveis. In: REDE DE TECNOLOGIA SOCIAL. (Brasil) (Org.). Tecnologia Social e Desenvolvimento Sustentável. Brasília: Secretaria Executiva da Rede de Tecnologia Social, 2010. p.85-91.

IAIES, G. Introdução de novas tecnologias: o caso da Argentina. In: TEDESCO, J. C. (org.). Educação e Novas Tecnologias: esperança ou incerteza? São Paulo: Cortez. 2004.

KAFURE, I., CUNHA, M..Usabilidade em ferramentas tecnológicas para o acesso à informação. Revista ACB: Biblioteconomia em Santa Catarina, Florianópolis, v.11, n.2, p. 273-282, ago./dez., 2006. Disponível em:< http://revista.acbsc.org.br/index.php/racb/article/view/483> Acesso em: 10 de dez. 2010.

MIRANDA, A. L. C. Ciência da Informação: teoria e metodologia de uma área em expansão. Brasília: Thesaurus, 2003.

MIRANDA, Silvânia Vieira. Identificando competências Informacionais. Ciência da Informação, Brasília, v. 33, n. 2, p. 112-122, maio/ago. 2004. Disponível em: <http://www.scielo.br/pdf/ci/v33n2/a12v33n2.pdf>. Acesso em 20 de dez. 2010. 
- Como as necessidades de informação podem se relacionar com as competências informacionais. Ciência da Informação, Brasília, v. 35, n. 3, p. 99-114, set./dez. 2006. Disponível em: <http://www.scielo.br/pdf/ci/v35n3/a12v35n3.pdf>. Acesso em 27 de dez. 2010.

OTTERLOO, A. M. da C. A tecnologia a serviço da inclusão social e como política pública. In: REDE DE TECNOLOGIA SOCIAL. (Brasil) (Org.). Tecnologia Social e Desenvolvimento Sustentável. Brasília: Secretaria Executiva da Rede de Tecnologia Social, 2010. p. 17-24. ROCHA, Carolini da. et al. Abordagens das Revistas Brasileiras de Ciência da Informação e Biblioteconomia a Respeito do Letramento Informacional. Revista ACB: Biblioteconomia em Santa Catarina, Florianópolis, v.13, n.1, p.145-158, jan./jun., 2008. Disponível em: <revista.acbsc.org.br/index.php/racb/article/download/544/669>. Acesso em: 26 de dez. 2010.

SIMEÃO, E. L. M. S. Comunicação extensiva e informação em rede. Brasília: CID/UnB, 2006.

; MIRANDA, A. L. C. (orgs.). Alfabetização digital e acesso ao conhecimento. Brasília: CID/UNB, 2006. 